\title{
Genomic deletions upstream of lamin B1 lead to atypical autosomal dominant leukodystrophy
}

Neurol Genet 2019;5:e362. doi:10.1212/NXG.0000000000000362

In the article "Genomic deletions upstream of lamin B1 lead to atypical autosomal dominant leukodystrophy” by Nmezi et al., ${ }^{1}$ first published January 24, 2019, the funding statement for Bruce Nmezi and Quasar S. Padiath should have included NIH (R01NS095884). The authors regret the error.

\section{Reference}

1. Nmezi B, Giorgio E, Raininko R, et al. Genomic deletions upstream of lamin B1 lead to atypical autosomal dominant leukodystrophy. Neurol Genet 2019;5:e305. doi: 10.1212/NXG.0000000000000305. 


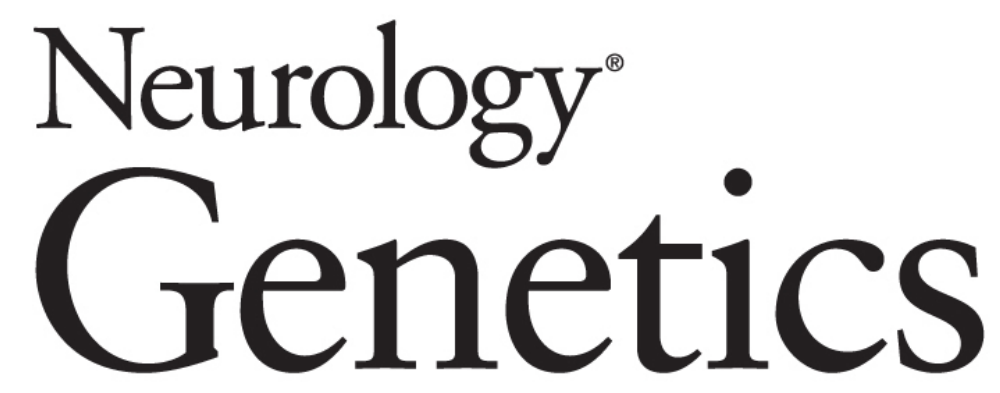

\section{Genomic deletions upstream of lamin B1 lead to atypical autosomal dominant leukodystrophy \\ Neurol Genet 2019;5; \\ DOI 10.1212/NXG.0000000000000362}

This information is current as of September 23, 2019

$\begin{array}{ll}\begin{array}{l}\text { Updated Information \& } \\ \text { Services }\end{array} & \begin{array}{l}\text { including high resolution figures, can be found at: } \\ \text { http://ng.neurology.org/content/5/5/e362.full.html }\end{array} \\ \text { References } & \begin{array}{l}\text { This article cites } 1 \text { articles, } 1 \text { of which you can access for } \\ \text { http://ng.neurology.org/content/5/5/e362.full.html\#\#ref-list }\end{array} \\ \text { Permissions \& Licensing } & \begin{array}{l}\text { Information about reproducing this article in parts (figures, } \\ \text { its entirety can be found online at: } \\ \text { http://ng.neurology.org/misc/about.xhtml\#permissions }\end{array} \\ \text { Reprints } & \begin{array}{l}\text { Information about ordering reprints can be found online: } \\ \text { http://ng.neurology.org/misc/addir.xhtml\#reprintsus }\end{array}\end{array}$

Neurol Genet is an official journal of the American Academy of Neurology. Published since April 2015, it is an open-access, online-only, continuous publication journal. Copyright ( 2019 American Academy of Neurology. All rights reserved. Online ISSN: 2376-7839.

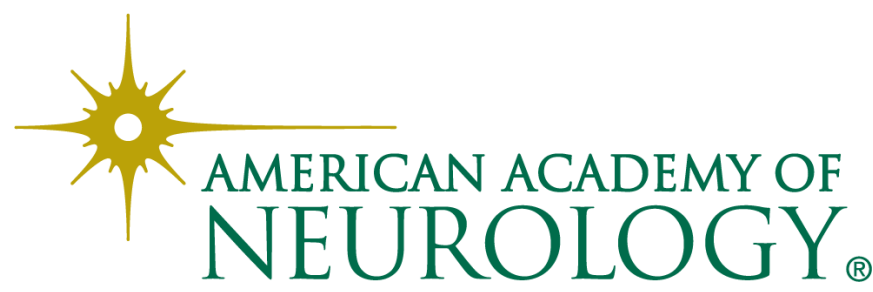

